\title{
A EXPERIÊNCIA DA PESQUISA PARA A INICIAÇÃO CIENTÍFICA
}

\section{THE RESEARCH EXPERIENCE THROUGH THE UNDERGRADUATE SCIENTIFIC RESEARCH PROGRAMS}

\author{
Clarissa Menna Barretoa \\ João Pedro Quaresma ${ }^{b}$ \\ Juliana Tuninc
}

\begin{abstract}
RESUMO
Introdução: O presente artigo apresenta um panorama geral da Iniciação Científica (IC) e Iniciação Científica Júnior (ICJ) no Brasil e da sua contribuição tanto para o bolsista quanto para a sociedade do país. Ademais, contém reflexões, baseadas na experiência dos autores, acerca da trajetória percorrida pelo estudante que decide participar do programa de IC ou ICJ. Objetivo: Promover conhecimento e reflexão sobre a participação da Iniciação Científica na estruturação e evolução das pesquisas científicas, além do próprio aprimoramento das faculdades críticas e do discernimento científico dos estudantes bolsistas. Metodologia: A reflexão proposta foi realizada a partir de um relato de experiência da atuação de Clarissa Menna Barreto, bolsista de Iniciação Científica, e João Pedro Quaresma, bolsista de Iniciação Científica Júnior, na pesquisa Comunicação e Infância, sob coordenação da pesquisadora Prof ${ }^{a}$. Dr ${ }^{a}$. Juliana Tonin. Resultados: A experiência da Iniciação Científica, por oferecer ao estudante a oportunidade de realizar um primeiro contato com o universo da pesquisa e da pós-graduação e de protagonizar o fazer-ciência, possibilita ao bolsista o desenvolvimento de um perfil crítico-investigativo próprio de um pesquisador e, por extensão, fomenta o interesse e a preocupação pela educação e pela ciência no país. Conclusão: A Iniciação Científica representa tanto uma experiência valiosa em âmbito pessoal quanto um elemento importante para a sociedade como um todo, ao auxiliar na construção de um país mais comprometido com a ciência e a educação.
\end{abstract}

Descritores: Iniciação Científica. Experiência. Pesquisa.

a Graduanda em Publicidade e Propaganda pela Pontifícia Universidade Católica do Rio Grande do Sul (PUC-RS). E-mail: mennabarretoclarissa@gmail.com.

b Graduando em Comunicação Social- Publicidade e Propaganda pela Universidade Federal do Rio Grande do Sul (UFRGS). E-mail: joaopquaresma12@gmail.com.

c Doutora em Comunicação Social pela Pontifícia Universidade Católica do Rio Grande do Sul (PUC-RS). Docente do Programa de Pós- graduação em Comunicação Social da Pontifícia Universidade Católica do Rio Grande do Sul (PUC-RS). E-mail: juliana.tonin@pucrs.br. 


\section{INTRODUÇÃO}

A Iniciação Científica (IC) pode ser descrita como "um processo no qual é fornecido o conjunto de conhecimentos indispensáveis para iniciar o jovem nos ritos, técnicas e tradições da ciência" (MASSI; QUEIROZ, 2010, p. 174). Consistindo na integração de saberes práticos e teóricos da ciência, ela aproxima o bolsista do ambiente da pós-graduação. Através das atividades desenvolvidas, torna-se possível um aprofundamento em outras áreas do saber e uma familiarização com a estruturação de uma pesquisa própria ou, como é percebido mais comumente, com os projetos de pesquisa em andamento desenvolvidos por professores pesquisadores.

A participação dos graduandos em pesquisas já é quase centenária, uma vez que tenha surgido juntamente com as próprias Instituições de Ensino Superior (IES) do país, na década de 30. As universidades brasileiras buscaram inspiração na estruturação de programas similares em países como Estados Unidos e França (BAZIN, 1983), cujas atividades de pesquisa já estavam bem consolidadas para que, com a criação do Conselho Nacional de Desenvolvimento Científico e Tecnológico (CNPq) em 1951, pudessem ser formalizadas e, em 1963, financiadas aos estudantes que viriam a ser bolsistas de Iniciação Científica. A partir de 1988, as bolsas de pesquisa, que antes eram distribuídas perante solicitação de pesquisadores, começaram a ser concedidas anualmente em quantidades fixas pelo Programa Institucional de Bolsas de Iniciação Científica (PIBIC) para Instituições de Ensino Superior (IES) e Institutos de Pesquisa (IPq) interessados. Para tanto, segundo Massi e Queiroz (2015, p. 7),

As instituições deveriam, então, criar seus próprios dispositivos de distribuição das bolsas aos seus pesquisadores que indicavam estudantes para atuar em seus projetos de pesquisa, bem como promover simpósios anuais para a apresentação dos trabalhos produzidos.

Esta medida significou um aumento exponencial de bolsistas participando de projetos de pesquisa por todas as universidades vinculadas, em que, atualmente, são disponibilizadas 27 mil bolsas para Iniciação Científica (CNPQ, 2019). Apesar de haver uma progressão na visibilidade do programa e 
nos seus beneficiários, nota-se que não existem muitas publicações que tratem sobre a Iniciação Científica no Brasil, ainda mais sob a perspectiva dos bolsistas. O estudo publicado pelas autoras Massi e Queiroz intitulada "Estudos sobre Iniciação Científica no Brasil: uma revisão" traz dados e relatos primordiais para a compreensão das contribuições da Iniciação Científica, junto à colaboração de outros pesquisadores da área. Diante do material levantado, as autoras trouxeram pontos-chave sob a ótica de diversos autores que valem ser retratados por explicitarem a importância da Iniciação Científica para os estudantes envolvidos e para o todo.

A Iniciação Científica representa uma experiência construtiva e importante para o estudante, visto que o introduz ao universo da pesquisa e da pós-graduação de maneira totalmente imersiva, colocando-o como protagonista do fazer científico e impulsionando o seu interesse pela pesquisa e pela ciência. Além disso, a IC promove a união entre a pesquisa e a sala de aula, muitas vezes vistas sob uma ótica que as compreende como distintas e imiscíveis, apresentando uma nova perspectiva ao aluno, a qual pode transformar o seu olhar sobre os conhecimentos adquiridos em sala de aula, refletindo em um melhor desempenho de sua parte. Como pontua Breglia (2002, p. 64 apud MASSI; QUEIROZ, 2010, p. 180), a possibilidade de integração do espaço da IC com a sala de aula ao representar a

[...] construção de uma via de mão dupla entre ensino e pesquisa, vai além de estabelecer entre eles uma relação de interdependência: também aporta um novo significado ao ensino de graduação, ao visualizar a sala de aula como mais um espaço de construção do conhecimento.

Os benefícios concedidos pela Iniciação Científica, entretanto, não atuam apenas a curto prazo: ao inserir-se no universo da pesquisa, o estudante tem a oportunidade de desenvolver e aprimorar um senso crítico-investigativo próprio de um pesquisador e de socializar com profissionais da área em que se entra em contato, fatores que poderão ser-Ihe úteis em sua vida profissional, seja ela relacionada ou não com a pesquisa. Essa caminhada de aprendizado pela ciência pode começar antes mesmo da graduação, através do Programa Institucional de Bolsas de Iniciação Científica para o Ensino Médio (PIBIC-EM), com a Iniciação Científica Júnior. 
Criada em 2003 (OLIVEIRA; BIANCHETTI, 2018, p. 141), a modalidade de bolsas de Iniciação Científica Júnior (ICJ) surgiu como um estímulo ao interesse tecnológico e científico no Brasil e, por extensão, age como uma alavanca da produção científica no país. Apresentando como objetivo principal a aproximação do estudante de Ensino Básico com o ambiente acadêmico, essa modalidade pretende "identificar e inserir 'vocações para a pesquisa' desde o ensino médio, garantindo a concessão de bolsas por meio de convênios com as fundações de apoio à pesquisa e/ou com as secretarias estaduais de ciência e tecnologia nos diferentes estados da federação." (SANTOS, 2013, p. 47). Desse modo, a ICJ oferece inúmeros benefícios à vida acadêmica do bolsista, uma vez que permite um primeiro contato com o cenário universitário e com a produção de pesquisas em tal ambiente antes mesmo do ingresso no Ensino Superior, por meio de uma inserção temporária em pesquisas desenvolvidas nas universidades brasileiras e da oportunidade de trabalhar ao lado do próprio pesquisador.

A pesquisa Comunicação e Infância tem como objetivo geral compreender o lugar, enquanto entendimento, da Infância nos estudos da Comunicação. Esse estudo teve início no segundo semestre de 2016 e está sendo executado em fases, sendo a primeira delas um levantamento quantitativo e análise qualitativa de todas as pesquisas que abordam temas da Infância produzidas na área da Comunicação desde o início da Pós-Graduação em Comunicação no Brasil, abrangendo trabalhos datados de 1970, até o ano de 2016, publicados enquanto teses ou dissertações e disponibilizadas em repositórios de Programas de Pós-Graduação (PPGs) por universidades de todo o Brasil, ou enquanto artigos científicos, publicados em revistas científicas da área, classificadas pelo Qualis Capes em B2, B1, A2, A1. Da mesma forma, houve também o levantamento de projetos de pesquisa relacionados ao tema, desenvolvidos por professores pesquisadores em todos os PPGs de Comunicação do país. Os principais objetivos da pesquisa são compreender qual é a participação da Infância nos estudos da Comunicação e, nos estudos que relacionam Comunicação e Infância, quais são as ênfases que podem ser identificadas. 
Do princípio da pesquisa até o presente momento, duas bolsistas de Iniciação Científica e quatro bolsistas de Iniciação Científica Júnior participaram dessa trajetória exercendo atividades diversas. Em cada fase houve demandas diferentes em função do material a ser trabalhado. A primeira aluna foi Anna Ortega, vinda do 2o. Ano do Ensino Médio do Colégio Marista Rosário, e primeira bolsista de IC Júnior da Escola de Comunicação, Artes e Design Famecos. Selecionada no segundo semestre de 2016, ela, junto à professora orientadora, começaram o projeto mapeando tudo o que havia sido produzido sobre a Infância no campo da Comunicação.

Numa entrevista realizada para compreender a experiência enquanto primeira bolsista, Ortega ressaltou que esta foi a primeira vez em que houve contato com o mundo acadêmico e da pesquisa. Para realizar a tarefa inicial que the foi incumbida, foi necessário conhecer todos os Programas de PósGraduação do país, para então descobrir quais dessas universidades dispunham de repositórios com seus trabalhos acadêmicos viabilizados online. Segundo a estudante, alguns sistemas de pesquisa eram mais interativos e acessíveis do que outros, o que poderia vir a facilitar ou dificultar a conferência dos dados. Dessa forma, foi necessária uma checagem manual em cada um desses programas para conferir se os trabalhos produzidos estavam disponibilizados. A antiga bolsista pontuou este ter sido um trabalho muito minucioso, que requeria muita atenção e sistematização para que isso pudesse virar uma fonte de informação, mas que entendeu quão imprescindível foi criar bases sólidas para as próximas fases da pesquisa.

A ex-aluna relata que aprendeu a dinâmica desses repositórios, a pesquisar trabalhos e projetos da área, além de se familiarizar com a linguagem acadêmica; a experiência foi uma abertura de caminhos para perceber que a pesquisa tem muitos desdobramentos e fases, mas que todas são importantes, inclusive que criar um banco de dados é trabalhoso, ainda que fundamental para construir um resultado de pesquisa consistente. Mais ainda, foi de grande aprendizado abrir os olhos para o universo da Infância, além de ser muito interessante a compreensão - ao reunir os dados e informações de cada IES —como a pesquisa sobre Infância se manifesta e é 
retratada por região do Brasil, por gênero de pesquisa, por pesquisador e demais recortes. "Foi um privilégio fazer parte dessa experiência ainda no Ensino Médio. De manhã estudava português, matemática, e de tarde, estava imersa no mundo acadêmico, transitando e me relacionando com mestrandos e doutorandos, pesquisando sobre Infância" (ORTEGA, 2020).

Depois dessa experiência, a antiga bolsista entende que atuar nessa pesquisa foi um divisor de águas pensando em sua experiência enquanto estudante de EM. Concluindo essa etapa, ela participou do Salão de Iniciação Científica Júnior, um evento em que todos os bolsistas ICJ fazem apresentações sobre os projetos que integraram. Eleita como bolsista destaque desse salão, foi convidada no ano seguinte a participar mais uma vez do programa.

Ao reingressar na pesquisa Comunicação e Infância, no segundo semestre de 2017, Ortega juntou-se às alunas Gabriela Killian, bolsista júnior estudante do 1‥ Ano do Ensino Médio do Colégio Santa Inês e Victória Duarte, bolsista graduanda da Famecos. As três participaram da coleta de teses, dissertações, projetos de pesquisa e artigos, em repositórios de PPGCOMs e revistas de Comunicação, respectivamente, organizando a amostra dos três primeiros itens em planilhas de acordo com nome do autor, título do trabalho, temática, IES, região do país e ano de publicação. As classificações de temáticas foram criadas pela orientadora em função de compreender por quais ênfases, perspectivas e formas a Infância é retratada na Comunicação, para que mais tarde, fosse possibilitada uma análise qualitativa do material categorizado. Já a importância da classificação por IES, região e ano é a de permitir a análise de dados e interpretações posteriores a partir destes.

Por fim, em agosto de 2018, Lorenzo Mello, estudante do $2^{\circ}$. Ano do Colégio Marista Rosário, veio a participar como bolsista júnior em duas tarefas: organizar bibliotecas internas para as teses e dissertações, os projetos e os artigos previamente recolhidos e criar uma planilha com os artigos relacionados à Infância. A primeira foi de grande importância por ter disponibilizado o material necessário de forma ordenada para posteriores consultas, por exemplo, e para a posterior disponibilização online do banco de dados. Já a 
segunda, teve como objetivo identificar o número total de artigos sobre o tema publicados em revistas científicas da área e reconhecer principais autores e publicadores desses artigos na Infância e Comunicação. A partir disso, seria possível fazer análises sobre a distribuição desses estudos por região de publicação e a relação entre locais de formação e atuação dos autores relacionados à Infância.

Tendo feito um breve histórico da pesquisa Comunicação e Infância, pode-se, então, aprofundar nos relatos dos atuais bolsistas e das tarefas que vêm sendo por eles realizadas. Vale ressaltar que todos os bolsistas assinam um termo de sigilo e de propriedade intelectual da pesquisa por parte da pesquisadora, instituição e fomento, e que, por esta razão, dados específicos não serão divulgados. Diante do trabalho executado pelos antigos estudantes, foi possível que a graduanda da Famecos e bolsista de Iniciação Científica, Clarissa Menna Barreto, e o estudante João Pedro Quaresma, bolsista de Iniciação Científica Júnior, do 3ํan ano do Colégio Santa Dorotéia, pudessem assumir as demandas finais para encerramento da última fase de pesquisa, ainda em andamento, iniciada em agosto de 2019. Esta consiste em dois momentos: realizar a listagem e a categorização dos artigos previamente selecionados e prever a disponibilização online do banco de dados.

O primeiro momento é levantamento qualitativo dos artigos científicos relacionados à Infância e Comunicação publicados em revistas brasileiras classificadas pelo Qualis Capes em B2, B1, A2 e A1, com base na planilha já prevista pelo bolsista precedente, Mello; para tanto, os artigos foram analisados e organizados em uma tabela a fim de classificá-los com base em categorias preestabelecidas pela orientadora e, no decorrer da classificação, mais categorias foram sendo criadas para contemplar todas as abordagens identificadas. Para que tal organização fosse possível, cada artigo era individualmente analisado: o título, o resumo, as palavras-chave e, por último, uma leitura dinâmica; assim, dentre todas as categorias disponíveis, era escolhida aquela que melhor contemplava o assunto tratado pelo artigo.

Além do levantamento qualitativo, os estudantes também atuaram na etapa de divulgação científica, que consiste na transformação do banco de 
dados interno criado durante a trajetória da pesquisa, a partir dos materiais acumulados durante o levantamento quantitativo, em uma entrega pública a toda a comunidade científica da área da Comunicação. Com esse objetivo, foi realizada uma pesquisa para buscar referências em trabalhos de pesquisadores que disponibilizam publicamente os dados obtidos em suas pesquisas, a fim de procurar a melhor forma de criar uma plataforma digital para publicar o banco de dados e tornar a sua visualização fácil e dinâmica. Assim, um site começou a ser arquitetado para sitiar as publicações do banco, as quais estarão dispostas em ordem cronológica.

Depois disso, será feita uma conferência desses artigos por meio de testes para checar se sua categorização ocorreu sem equívocos, com previsão de finalização em maio de 2020. Após o encerramento dessa fase, será lançado um livro pela professora orientadora, cujas interpretações qualitativas serão contempladas junto às análises deste material reunido pelos bolsistas.

\section{RELATO DE EXPERIÊNCIAS}

Imersos na pesquisa, os bolsistas Menna Barreto e Quaresma se depararam com algumas novidades e desafios. Ao participar de um projeto já em andamento, foi possível apreender novas maneiras de organização de trabalho e rotinas específicas, uma vez que demandas surgiam e precisavam de novas disposições de tempo e de energia por parte dos bolsistas para realizá-las.

Também foi possível, através do contato com a pesquisa aprofundada da professora, que os alunos pudessem compreender a composição de um banco de dados em sua essência, assim como o impacto de sua disponibilização para a comunidade acadêmica. Por meio disso, as etapas da criação e da estruturação deste banco ficaram claras e, atuando nele, pôde-se perceber a importância deste trabalho: no âmbito macro, para a academia, para pesquisadores, e para a sociedade como um todo; já no micro, contempla-se os alunos envolvidos diretamente com o banco, percebendo que essa inserção no processo é importante para entender as noções de como se dão as bases desse sistema, a exemplo da composição de categorias, organização de 
trabalhos heterogêneos com assuntos em comum, realização de buscas específicas em outros bancos e aprofundamento em metodologias de pesquisa. Além de conhecerem repositórios de universidades de todo o país e os respectivos pesquisadores que atuam na área da Comunicação, os quais contribuem com o conhecimento e com o trabalho que fazem para toda a comunidade, é de grande importância ressaltar como o contato com os estudos publicados trouxe novas perspectivas para os estudantes: familiarizar-se com conceitos científicos e realidades acadêmicas; saber discernir qualidade de produções através do Qualis Capes; conhecer revistas da área da Comunicação e descobrir novos caminhos de pesquisa.

É de alta relevância ter a noção do que vem sendo produzido no país nas últimas décadas sobre a Infância e Comunicação, junto a tantos outros temas relacionados, o que leva os estudantes bolsistas a reflexões e questionamentos próprios. Questionamentos, estes, que podem começar desde cedo - no Ensino Médio, no caso do bolsista júnior - e que virão a ser desdobrados na pós-graduação. Aí surge, muitas vezes, o ímpeto de inserir-se no mundo da pesquisa. Dados levantados por Cabrero (2007) em sua tese de doutorado sobre os egressos do PIBIC e sua relação com a pós-graduação apontam que, em sua universidade de atuação, Universidade Federal de São Carlos (UFSCar), metade dos ex-bolsistas de IC havia tornado à pósgraduação desde o início do programa em 1992. Da mesma forma, em pesquisa solicitada pela CNPq, Aragón, Martins e Velloso (1999, p. 34 apud MASSI; QUEIROZ, 2010, p. 12) relatam que um ex-aluno bolsista tem seis vezes mais probabilidade de retornar à pós-graduação, "porque 3 em cada 10 bolsistas Pibic chegam ao mestrado [...] o prazo médio de transição entre a conclusão da graduação e o ingresso no mestrado, para um ex-bolsista Pibic, é de 1,2 ano", o que é mais rápido do que os estudantes que não se vincularam ao programa de IC durante os anos de faculdade.

É interessante analisar a própria trajetória do estudante que vem a se tornar bolsista. Bazin (1983) relata situações corriqueiras do seu meio, o Departamento de Física da PUC-Rio, demonstrando o processo evolutivo do estudante cujo caminho é transpassado pela pesquisa. $O$ aluno ingressa na 
faculdade vindo de um ambiente de passividade, em que o conteúdo ensinado é uma verdade, uma premissa, "É um receber passivo de um outro saber que os outros têm." (BAZIN, 1983, p. 83). Cabe, então, ao professor orientador instigá-lo a romper com a forma de pensamento escolar e suscitar a construção de novos caminhos e perspectivas durante o período de faculdade. Como comenta Bazin, a IC pode ser uma chave para a independência intelectual do estudante, uma vez que ele comece a questionar o que consome, o material com que trabalha e os conhecimentos postulados em sua área.

Parece fundamental ressaltar que o papel de protagonismo assumido pelos bolsistas durante a pesquisa foi dado e incentivado pela orientadora, de forma que ambos puderam se engajar e se aprofundar nas questões cerne da própria pesquisa Comunicação e Infância. Foi possível, por meio das práticas vivenciadas no coletivo, correlacionar as teorias aprendidas no presente estudo aos aprendizados em grupo, aproximando tudo da realidade e amplificando a dimensão do vivido através da dinâmica e do diálogo. Ambos participaram das atividades previstas para o semestre com os demais orientandos - mestrandos e doutorandos - da professora Juliana Tonin ao integrar o Laboratório de Pesquisas da Comunicação nas Infâncias, LabGim, criado em 2019 a partir da parceria com o Centro Marista de Promoção dos Direitos da Criança e do Adolescente e da Fundação Irmão José Otão (Fijo). Estas envolveram incursões a Centros Maristas parceiros e participações interdisciplinares com a Fundação Pão dos Pobres, o que primariamente possibilitou o encontro do bolsista com outras realidades e perspectivas sobre crianças e infâncias. Acredita-se que, por conta da aproximação da professora orientadora entre seus orientandos mestrandos e doutorandos com os bolsistas de Iniciação Científica no espaço físico do laboratório, foi permitido que o ambiente em si propiciasse trocas valiosas. $O$ contato com alunos em níveis de formação mais avançados e com suas pesquisas direcionadas aos temas da Infância auxiliou no processo tanto de assimilação da construção de uma pesquisa quanto na compreensão da materialização do que estava sendo observado e estudado por eles naquela instância.

Cada um também pôde exercitar demandas específicas, em paralelo 
com as atividades incumbidas: o bolsista júnior desempenhou as tarefas de organização, categorização e arquivamento de materiais coletados durante as experiências do grupo e a bolsista graduanda ficou responsável de fazer registros fotográficos, estruturar apresentações multimídia e identidades visuais.

Nessa perspectiva, a bolsista de Iniciação Científica, enquanto graduanda no curso de Publicidade e Propaganda, vivenciou este período de uma nova forma. No início de sua trajetória acadêmica, ela havia participado do programa de IC, integrando uma pesquisa com viés tecnológico, voltado para o mercado e para as respectivas inclinações dessa área. Muito deste posicionamento se deu pelos próprios caminhos de pesquisa traçados pelos professores que a orientaram, cujas áreas de interesse e pesquisa também seguiam neste viés. A principal diferença entre as duas vivências enquanto bolsista foi a de, em sua primeira oportunidade, escrever um artigo acadêmico próprio de acordo com quaisquer temas que estivessem contemplados na pesquisa maior. Já em sua segunda oportunidade, foi o de integrar uma pesquisa vigente, especificamente em sua fase final, compreendendo os processos e as etapas de estruturação de um projeto que vinha sendo desenvolvido há alguns anos. O desempenho de tarefas específicas, a organização de dados e o compartilhamento de relatos com o colega foram essenciais para que a bolsista compreendesse as principais diferenças entre as duas experiências e os aprendizados específicos que cada uma delas viria a Ihe proporcionar. Cabe ressaltar que, cursando o final de sua trajetória acadêmica, a bolsista teve a escolha sobre seu tema de monografia motivada também pela pesquisa em questão, e que ela se tornará mais uma autora a figurar nos estudos da Infância.

Já sobre Quaresma, pode-se perceber que o programa de Iniciação Científica Júnior permitiu ao estudante a oportunidade de atuar com protagonismo no universo da pesquisa científica. Participar da ICJ é uma experiência valiosa pois insere o estudante em meio acadêmico ainda antes de seu ingresso no Ensino Superior, o que possibilita que ele se familiarize com este universo: além das tarefas que diziam respeito diretamente ao projeto 
Comunicação e Infância, o bolsista também participou dos encontros dos integrantes e de ações do LabGim. Dessa forma, oportunizou-se uma imersão completa no ambiente do fazer científico em que as experiências vividas auxiliaram o estudante no desenvolvimento de um senso questionador e uma curiosidade científica diante dos conhecimentos que the eram apresentados; ou seja, possibilitaram o início da construção do perfil de alguém que poderá tornar-se um legítimo pesquisador - justamente o objetivo da Iniciação Científica Júnior. Os efeitos e as transformações desencadeados pela experiência do ICJ, entretanto, não se restringiram apenas às atividades desempenhadas durante período de seis meses no qual houve a atuação de Quaresma na pesquisa: tal experiência impactou sua percepção científica e despertou novos interesses no bolsista que, prestes a prestar vestibular para o curso de cinema e audiovisual, foi instigado pela possibilidade de um projeto próprio que pensasse conteúdos de filmes para as infâncias - mas que não se firmou, por enquanto, como um projeto de pesquisa concreto.

A experiência de um estudante que se insere no mundo acadêmico por meio da IC é válida e significativa em diversas instâncias, além de transformadora, também, em aspectos do próprio desenvolvimento do bolsista. Os seminários e apresentações de trabalho aos quais os bolsistas devem apresentar suas pesquisas e suas respectivas atuações são maneiras de aprimorar a fala e a eloquência do estudante que entra em contato com o mundo acadêmico. No caso dos bolsistas que participaram da pesquisa Comunicação e Infância, todos apresentaram seus respectivos projetos e contribuições no Salão de Iniciação Científica, um evento promovido pela universidade que "representa um espaço de socialização de atividades de pesquisa envolvendo estudantes da graduação e professores/pesquisadores de diferentes universidades e instituições de pesquisa regionais e/ou brasileiras" (PUCRS, 2019). O repertório de linguajar se expande em função dos textos científicos analisados e essa expansão vocabular pode ser percebida através da melhora da escrita dos textos produzidos durante 0 período da bolsa. A postura e a formalidade dos diferentes espaços em que se transita também ensina sobre respeito e manutenção das normas sociais do 
meio, permitindo um desenvolvimento do profissionalismo e de novas habilidades de comunicação, características essenciais a serem cultivadas pelo o pesquisador em formação.

Assimilando, enfim, quais são os aprendizados de um bolsista de Iniciação Científica e a importância de suas experiências (tanto para si mesmo, quanto para a comunidade acadêmica), é relevante compreender quais foram os principais desafios e aprendizagens para os estudantes atuando na pesquisa Comunicação e Infância. A principal problemática encontrada foi em relação aos desafios de tratamento dos dados, em alguns artigos que constavam no banco, na verdade, não tratavam essencialmente sobre Infância. Isso remonta a fases anteriores, em que outros bolsistas precisaram filtrar diversos de artigos de acordo com cinco palavras-chave: puer, criança, infantil, infanto e infância.

Diante da seleção por meio dos vocábulos, é possível que artigos de temas diversos da Comunicação constassem na lista de resultados por abranger apenas alguma das palavras-chave, mas sem necessariamente ter como tema central a questão da Infância. Em função disso, o trabalho dos bolsistas Menna Barreto e Quaresma precisou ser minucioso e cauteloso ao repassar quais artigos, de fato, falavam sobre Infância e poderiam se enquadrar nas categorias temáticas pré-estabelecidas. Esta foi uma questão que veio a diminuir o tempo para categorização dos trabalhos e o ritmo de execução, uma vez que tenha sido necessário que os bolsistas se debruçassem sobre os textos para lê-los e compreendê-los em sua totalidade. É relevante ressaltar que quaisquer equívocos cometidos fazem parte do processo e a busca pela menor margem de erro é horizonte da pesquisa e dos resultados que ela virá apresentar. Ainda assim, certamente por meio desse aprofundamento em leituras de ênfases diversas, houve uma grande expansão de conhecimentos sobre a área da Comunicação para os bolsistas envolvidos. Muitos artigos vinham ao encontro dos interesses próprios de cada um e seguramente suscitaram a busca e o despertar para novos saberes.

Retomando a categorização dos artigos científicos, apesar da consulta desta amostra ser majoritariamente dinâmica, houve dificuldade em manter 0 
ritmo entre leituras em função de um não costume com a escrita científica, uma vez que o bolsista de Iniciação Científica júnior estivesse experienciando um primeiro contato com termos específicos da área da Comunicação ou de quaisquer outras com que o tema do estudo viesse a dialogar. Isso veio a ressoar mais uma vez ao surgirem dúvidas em que forma classificar alguns artigos. A abrangência de certos temas requereu um trabalho lógico dos bolsistas, muitas vezes resultando em debates entre eles, levando-os a reformular classificações ou criar novas categorias. Em função dessas trocas, foi possível exercitar novas formas de categorização dos textos, principalmente por conta da compreensão e interpretação construídas por cada estudante.

Em suma, ao interagirem com a pluralidade da produção acadêmica analisada, imergirem no ambiente da pesquisa e protagonizarem o fazerciência, com todos os desafios próprios do cotidiano de um pesquisador, é inegável que os bolsistas passaram por uma crescente curva de aprendizado em termos de apropriação de saberes acadêmicos, o que possibilitou 0 aprimoramento das faculdades críticas e do discernimento científico dos estudantes.

Acredita-se que uma das maiores contribuições para o desenvolvimento dos bolsistas dentro da pesquisa foi o de poderem trocar entre si e entre os outros integrantes do grupo LabGim as suas percepções e saberes obtidos durante o processo do pesquisar. Desse modo, é compreensível que houve aprendizados afins e experiências significativas para os bolsistas, mas que, ainda assim, estes foram impactados de formas diferentes, em função da trajetória particular de cada bolsista e dos distintos momentos da vida estudantil vivenciados por cada um.

É inegável que através da compreensão da importância das atividades desempenhadas por bolsistas em seu nicho de atuação dentro do projeto que integram e do impacto que essa atuação causa na pesquisa brasileira, se faz fundamental conceber as dimensões que um programa como o PIBIC pode tocar e transformar na atual realidade do país. Dar ao jovem estudante de Ensino Médio ou de graduação a oportunidade de investir numa carreira enquanto cientista é mais que necessário. Em nível pessoal, é uma experiência 
que agrega saberes das mais diversas áreas, tanto teóricos quanto práticos, e que suscita de diversas formas a busca de aprimoramento próprio e, consequentemente, coletivo. Em termos de sociedade, o estímulo e o fomento à pesquisa se fazem vitais para o desenvolvimento da educação, da ciência e do futuro promissor de um país.

\section{CONSIDERAÇÕES FINAIS}

Por meio do presente artigo, acredita-se que foi possível analisar e compreender como se deu a experiência de Iniciação Científica dos bolsistas durante seu período vinculados à pesquisa da professora Juliana Tonin.

Através do contato com a pesquisa Comunicação e Infância, os estudantes se depararam, em um primeiro momento como levantamento e a categorização de artigos científicos e a criação do banco de dados. Além disso, eles puderam vivenciar diferentes formas de pesquisar, tanto na teoria, como previamente citado, quanto na prática, ao integrar o LabGim e suas atividades durante o semestre, interagindo com mestrandos e doutorandos da área, o que possibilitou uma conexão entre o conhecimento teórico adquirido e as vivências experienciadas.

A partir de buscas por respostas válidas e completas para quaisquer questionamentos que viessem à tona, os bolsistas puderam exercer com autonomia as atividades que Ihes foram designadas. Assim, reconhecer o lugar dos bolsistas de IC e ICJ na pesquisa como um todo também é ressaltar que todos os dados levantados e consultados são de extrema relevância. Pode-se entender, então, o investimento na Iniciação Científica como um investimento no futuro da pesquisa dentro de uma sociedade.

\section{REFERÊNCIAS}

BAZIN, Maurice Jacques. O que é a iniciação científica. Revista de Ensino de Física, São Paulo, v. 5, n. 1, p. 81-88, jun. 1983.

CABRERO, Rodrigo de Castro. Formação de pesquisadores na UFSCar e na área de Educação Especial: impacto do programa de iniciação científica do 
CNPq. 2007. 276 f. Tese (Doutorado em Ciências Humanas) - Universidade Federal de São Carlos, São Carlos, 2007.

CNPQ suspende 4.500 bolsas por falta de orçamento. 0 Globo, Rio de Janeiro, 15 de ago. 2019. Disponível em:

https://oglobo.globo.com/sociedade/educacao/cnpq-suspende-4500-bolsas-porfalta-de-orcamento-23880009. Acesso em: 11 jan. 2020.

MASSI, Luciana; QUEIROZ, Salete Linhares. Estudos sobre iniciação científica no Brasil: uma revisão. Cadernos de Pesquisa, São Paulo, v. 40, n. 139, p. 173-197, abr. 2010. DOI: http://dx.doi.org/10.1590/S010015742010000100009. Disponível em: http://www.scielo.br/scielo.php?script=sci_arttext\&pid=S0100$15742010000100009 \&$ Ing=en\&nrm=iso\&tIng=pt. Acesso em: 06 jan. 2020.

MASSI, Luciana; QUEIROZ, Salete Linhares. Iniciação científica: aspectos históricos, organizacionais e formativos da atividade no ensino superior brasileiro. São Paulo: Ed. da Unesp digital, 2015. Disponível em: http://books.scielo.org/id/s3ny4. Acesso em: 11 jan. 2020.

PUCRS. 20 SALÃO DE INICIAÇÃO CIENTíFICA. Porto Alegre, 2019. Disponível em: http://www.pucrs.br/eventos/inst/salaoic/. Acesso em: 21 jan. 2020.

OLIVEIRA, Adriano de; BIANCHETTI, Lucídio. Iniciação Científica Júnior: desafios à materialização de um círculo virtuoso. Ensaio: Avaliação e Políticas Públicas em Educação, Rio de Janeiro, v. 26, n. 98, p. 133-162, 2018. DOI: http://dx.doi.org/10.1590/s0104-40362018002600952.

ORTEGA, Anna. Vivência sobre Iniciação Científica Júnior: Depoimento. [Entrevista cedida pessoalmente a] Clarissa Menna Barreto. Porto Alegre, jan. 2020.

SANTOS, Silvia Alves dos. Mudanças na graduação na universidade pública: a nova prática da iniciação científica. 2013. 126 f. Tese (Doutorado em Ciências Humanas) - Universidade Federal de São Carlos, São Carlos, 2013.

\title{
THE RESEARCH EXPERIENCE THROUGH THE UNDERGRADUATE SCIENTIFIC RESEARCH PROGRAMS
}

\begin{abstract}
Introduction: This article presents a general view of the Undergraduate Research (IC) and High School Research Assistant (ICJ) programs situation in Brazil and its contributions to the student enrolled in the program and to the society. Furthermore, the present study contains reflections based on the perspective of its authors regarding the experience of being a student that decides to get involved with research through IC
\end{abstract}


and ICJ. Objective: To promote knowledge and reflections about the Undergraduate Research students participation in structuring of a scientific research, besides the enhancement of their critical thinking skills and scientific discernment. Methodology: The reflection proposed in this study comes from an experience report of Clarissa Menna Barreto's - Undergraduate Research student — and João Pedro Quaresma's - High School research assistant - participation in the research "Childhood and Communication", led by researcher Juliana Tonin. Results: The Undergraduate Research scholarship, for offering to the student the opportunity to try a first contact with the scientific research and graduate studies environment and the chance to embody the everyday life of a true researcher. Conclusions: The Undergraduate Research program represents a valuable experience for both the student and society, as it helps to build a country more committed to science and education.

Descriptors: Undergraduate Scientific Research. Experience. Research.

\title{
LA EXPERIENCIA DE INVESTIGACIÓN ACADÉMICA PARA LOS PROGRAMAS DE INICIACIÓN CIENTÍFICA
}

\begin{abstract}
RESUMEN
Introducción: Este artículo presenta una visión general de los programas de Iniciación Científica (IC) y Iniciación Científica Junior (ICJ) en Brasil y sus contribuciones al estudiante inscrito en el programa y a la sociedad. Además, el presente estudio contiene reflexiones basadas en la perspectiva de sus autores con respecto a la experiencia de ser un estudiante que decide involucrarse en la investigación a través de IC y ICJ. Objetivo Promover el conocimiento y las reflexiones sobre la participación de los estudiantes de Iniciación Científica en la estructuración de una investigación científica, además de la mejora de sus habilidades de pensamiento crítico y discernimiento científico. Metodología: La reflexión propuesta en este estudio proviene de un informe de experiencia de Clarissa Menna Barreto, alumna becaria de Iniciación Científica, y João Pedro Quaresma, becario de Iniciación Científica Junior, participación en la investigación "Comunicación y Infancia", dirigida por la investigadora Juliana Tonin. Resultados: El programa de Iniciación Científica, por ofrecer al estudiante la oportunidad de intentar un primer contacto con el entorno de investigación científica y estudios de posgrado y la oportunidad de conocer la vida cotidiana de un verdadero investigador. Conclusiones: La Iniciación Científica representa una experiencia valiosa tanto para el estudiante como para la sociedad, ya que ayuda a construir un país más comprometido con la ciencia y la educación.
\end{abstract}

Descriptores: Iniciación Científica. Experiencia. Investigación.

Recebido em:04.02.2020

Aceito em: 05.02.2021 